\title{
Temporary solution for one lung ventilation with isolated bronchial blocker of Univent ${ }^{\circledR}$ tube
}

\author{
Junyong In, Moon-Ki Park, and Jin Han \\ Department of Anesthesiology and Pain Medicine, Dongguk University Ilsan Hospital, Goyang, Korea
}

One lung ventilation (OLV) is a commonly used technique to accomplish surgical visualization during thoracic surgical procedures, and is often required unexpectedly during surgery. In most cases, OLV is done with through intraoperative tube change, or with various bronchial blockers (BBs) $[1,2]$. However, if changing the tube is not possible (e.g. active oral bleeding, or severe intraoral edema), or, even worse, if the BBs are not prepared (less prepared conditions, or emergency situations), intermittent two lung ventilation (TLV) or high frequency jet ventilation (HFJV) is the last choice [3].

A 48 -year-old $(178 \mathrm{~cm}, 68 \mathrm{~kg})$ man was scheduled for emergency surgical drainage of a deep neck infection. For the postoperative airway management, awake nasal intubation was selected. The oropharyngeal mucous membranes were topically anaesthetized with $4 \%$ lidocaine. This was supplemented with shallow sedation using intravenous infusion of dexmedetomidine $1 \mathrm{mcg} / \mathrm{kg}$ for 10 minutes. Fiberoptic intubation through the nose was performed with a 7.0 wirereinforced endotracheal tube (ETT).

Anesthesia was induced with propofol and vecuronium, maintained with a mixture of desflurane and oxygen $\left(\mathrm{FiO}_{2} 0.4\right)$ and remifentanil infusion. TLV was started with tidal volume of $10 \mathrm{ml} / \mathrm{kg}$ at $12 \mathrm{rates} / \mathrm{min}$. Initial body temperature was $39.0^{\circ} \mathrm{C}$ and peak airway pressure was $18 \mathrm{cmH}_{2} \mathrm{O}$.

Because the abscess drainage was not adequate, it was decided to do further drainage through a thoracoscopy. But changing to a double lumen tube (DLT) or a Univent ${ }^{\circledR}$ tube (Fuji system corp., Tokyo, Japan) was impossible due to severe intraoral edema. BBs and Fogarty catheter were not prepared.
Intermittent TLV was applied initially, but because of the inadequate visualization of the operative field, we tried to use a BB housed in the Univent ${ }^{\circledR}$ tube, extracted by cutting the main tube. The BB and the fiberoptic bronchoscopy (FB) were too bulky to enter the ETT together, so after measuring the approximate distance from the orifice of the ETT to the carina and to the left main bronchus with the FB, the BB was inserted blindly. The balloon was inflated incrementally until adequate OLV was confirmed with auscultation. A short corrugated tube was connected to the ETT because the BB was longer than the ETT (Fig. 1). The short corrugated tube was semitransparent

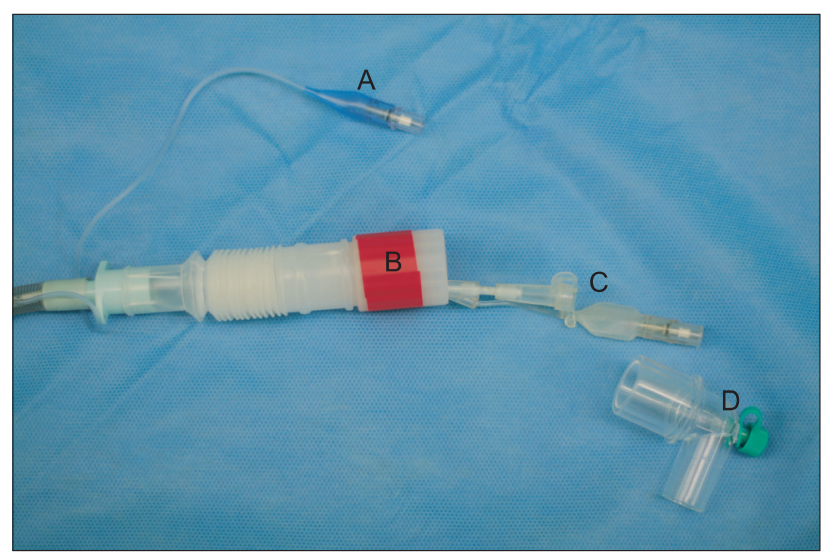

Fig. 1. Short corrugated tube is used as an extension to connect the endotracheal tube with the breathing circuit. (A) Endotracheal tube, (B) Short corrugated tube, (C) Separated bronchial blocker, (D) Connector of breathing circuit.

Corresponding author: Junyong In, M.D., Department of Anesthesiology and Pain Medicine, Dongguk University Ilsan Hospital, 814, Siksadong, Ilsandong-gu, Goyang 410-773, Korea. Tel: 82-31-961-7875, Fax: 82-31-961-7864, E-mail: dragona1@dumc.or.kr

(c) This is an open-access article distributed under the terms of the Creative Commons Attribution Non-Commercial License (http:// creativecommons.org/licenses/by-nc/3.0/), which permits unrestricted non-commercial use, distribution, and reproduction in any medium, provided the original work is properly cited. 
and had a large internal diameter, so it did not disturb the position of the BB. No adverse events were observed, and adequate OLV was maintained throughout $120 \mathrm{~min}$ of thoracoscopic procedure. Tidal volume was $700 \mathrm{ml}$ at $13 \mathrm{rates} / \mathrm{min}$. Peak airway pressures were well maintained between 25 and 28 $\mathrm{cmH}_{2} \mathrm{O}$. After completing the drainage, we removed the $\mathrm{BB}$ and ventilated both lungs with the ETT. The patient was cared for in the intensive care unit after surgery. On the sixth day after the operation, the patient was extubated and showed no respiratory complications.

In modern practice, left-sided DLT is most widely accepted to facilitate OLV. Independent BBs and a Univent ${ }^{\circledR}$ tube are also reliable alternatives. However, there are certain cases when intubation with DLT is not possible, or when intraoperative tube change is not available. In those cases, independent BBs serve as ideal devices [4]. But in cases of emergency situations or less prepared conditions, BBs might be not available. The ETT can be advanced into the bronchus, but nasotracheal intubation does not allow it. Intermittent TLV or HFJV is the last choice.

Intermittent TLV is necessary when OLV is inadequate, but it will interrupt the surgery. HFJV does not hinder surgical procedure. A specific ventilator, a special adaptor, and an oxygen insufflation catheter, however, are required.

The BB housed in a small channel bored in the wall of the Univent ${ }^{\circledR}$ tube is longer than a standard ETT and has a bulky proximal end. Its distal end could be passed easily through the ETT, but the FB could not be passed together with it. So we estimated the distance from the connector of the ETT to the left main bronchus with FB, and the BB was then passed through the ETT blindly. Only indirect confirmation of the BB placement from auscultation will be available. Because the $\mathrm{BB}$ of the Univent ${ }^{\circledR}$ tube is somewhat stiff, gentle manipulation is required and it should not be advanced against significant resistance.

To connect the ETT and the connector of the breathing circuit, a short corrugated tube is a reliable device. It has a large internal diameter and its length can be easily controlled, so the bulky proximal end of the BB can be placed in it without increasing the airway pressure (Fig. 1).

In conclusion, the unhoused bronchial blocker of a Univent ${ }^{\circledR}$ tube with a short corrugated tube was a reliable temporary solution for OLV without independent BBs or a Fogarty catheter.

\section{References}

1. Campos JH. Which device should be considered the best for lung isolation: double-lumen endotracheal tube versus bronchial blockers. Curr Opin Anaesthesiol 2007; 20: 27-31.

2. Mungroop HE, Wai PT, Morei MN, Loef BG, Epema AH. Lung isolation with a new Y-shaped endobronchial blocking device, the EZ-Blocker. Br J Anaesth 2010; 104: 119-20.

3. Ender J, Brodowsky M, Falk V, Baunsch J, Koncar-Zeh J, Kaisers UX, et al. High-frequency jet ventilation as an alternative method compared to conventional one-lung ventilation using doublelumen tubes during minimally invasive coronary artery bypass graft surgery. J Cardiothorac Vasc Anesth 2010; 24: 602-7.

4. Slinger RD, Campos JH. Anesthesia for thoracic surgery. In: Miller's Anesthesia. 7th ed. Edited by Miller RD: Philadelphia, Elsevier Churchill Livingstone. 2010, pp 1819-87. 